\title{
Skin involvement in neuroendocrine neoplasia
}

\author{
Ana VALEA ${ }^{1,2}$, Florica SANDRU ${ }^{3,4}$, Simona Elena ALBU ${ }^{3,5}$, Mihai Cristian DUMITRASCU ${ }^{3,5}$, \\ Dana TERZEA ${ }^{6}$, Ana Maria Alexandra STANESCU 3 , Mara CARSOTE ${ }^{3,6}$ \\ ${ }^{1}$ Clinical County Hospital, Cluj-Napoca, Romania \\ 2"Iuliu Hatieganu" University of Medicine and Pharmacy, Cluj-Napoca, Romania \\ 3"Carol Davila" University of Medicine and Pharmacy, Bucharest, Romania \\ ${ }^{4}$ Elias Emergency University Hospital, Bucharest, Romania \\ ${ }^{5}$ Emergency University Hospital, Bucharest, Romania \\ "6.C.I. Parhon" National Institute of Endocrinology, Bucharest, Romania
}

\begin{abstract}
Neuroendocrine neoplasia (NEN), priory known as neuroendocrine tumours represent the modern approach of traditionally named "carcinoid" tumours. We shortly introduce benign and malign dermatological aspects that are linked to NEN field. This is a multidisciplinary perspective. The paper is a mini-review. 30 articles are included as references. NEN represents $2 \%$ of all cancers, being considered orphan disease. Skin and soft tissue are exceptional sites of NEN, the majority are actually secondary spreading of NEN of other locations. Little data have been published related to the topic. Some cases reports showed invasion of dermis and subcutis, probably more frequent in older adults. The entity has been named low-grade neuroendocrine carcinoma of the skin, also named primary cutaneous carcinoid tumour. As seen in NEN diagnosis, the immunohistochemistry is essential like chromogranin A, synaptophysin, neuron specific enolase which are classical neuroendocrine markers and non-neuroendocrine parameters are useful for differential diagnosis like estrogens, androgens and progesterone receptors, GATA3, carcinoembryonic antigen. Merkel cell carcinoma represents the high grade NEN. It has a poor prognosis, with a $30 \%$ risk of local metastasis. The risk factors are either viral infection like Merkel cell polyomavirus, either long time exposure to ultraviolet light. The prognostic is similar between the two factors. Surgical removal is the first line therapy and adjuvant treatment is radiotherapy and chemotherapy. Skin NEN represents an exceptional finding of aggressive profile. Their prompt recognition may help the prognosis.
\end{abstract}

Keywords: skin, neuroendocrine neoplasia, melanoma

\author{
Abbreviations \\ $\mathrm{G}=$ grading \\ $\mathrm{HPF}=$ high power field \\ LGNECS $=$ low-grade neuroendocrine \\ carcinoma of the skin \\ MEN $=$ multiple endocrine neoplasia \\ $\mathrm{NEC}=$ neuroendocrine carcinoma
}

\author{
$\mathrm{NEN}=$ neuroendocrine neoplasia \\ $\mathrm{NET}=$ neuroendocrine tumours \\ MiNEN $=$ mixed NEN/non-NEN \\ PCTS $=$ primary cutaneous carcinoid tumor \\ $\mathrm{WHO}=$ World Health Organisation
}




\section{INTRODUCTION}

Neuroendocrine neoplasia (NEN), priory known as neuroendocrine tumours (NET) represent the modern approach of traditionally named "carcinoid" tumours $(1,2)$. The topic is emergent, multidisciplinary, heterogeneous and extremely dynamic (1,3). In 2017 WHO (World Health Organisation) revised the criteria and the terminology $(1,4)$ (Figure 1). G1/G2 grade (or low/intermediate grade) is considered well-differentiated NEN depending on Ki67 value: less than $2 \%$ for G1 and the levels between 3 and $20 \%$ correspond to $\mathrm{G} 2$ while mitotic index (HPF= high power field) is less than 2/10, respective 2-20/10 (4). G3 (or high grade) may represent well-differentiated NEN with a Ki67 value more than $20 \%$ and a mitotic index of $>20 / 10$ or poorly differentiated NEN or neuroendocrine carcinoma (NEC) which including either small or large cells in addition to a Ki67 level higher than 20\% (4). WHO 2017 classification also introduces a new category: mixed NEN/non-NEN (MiNEN) as well as hyperplastic and preneoplasic lesions (4).

\begin{tabular}{|c|c|c|c|}
\hline Grade & Terminology & ki-67 (\%) & $\begin{array}{l}\text { Mitotic index } \\
\text { (HPF) }\end{array}$ \\
\hline G1 & \multirow{3}{*}{$\begin{array}{l}\text { Well- } \\
\text { differentiated } \\
\text { NEN }\end{array}$} & $<20$ & $<2 / 10$ \\
\hline G2 & & $3-20$ & $2-20 / 10$ \\
\hline \multirow{2}{*}{ G3 } & & \multirow{2}{*}{$>20$} & $>20 / 10$ \\
\hline & $\begin{array}{l}\text { Poorly } \\
\text { differentiated } \\
\text { NEN }\end{array}$ & & $\begin{array}{l}\text { Small or large } \\
\text { cells }\end{array}$ \\
\hline
\end{tabular}

FIGURE 1. WHO 2017 classification of neuroendocrine neoplasia (NEN)

\section{AIM}

We shortly introduce benign and malign dermatological aspects that are linked to neuroendocrine tumours field. This is a multidisciplinary perspective.

\section{METHOD}

The paper is a mini-review. 30 articles are included as references. Unselected PubMed research of "neuroendocrine neoplasia" showed 172,871 results and since 2017 a number of 6,577 papers have been published up to present with a remarkable progressive incidence since 1945 up to 2019 (5) (Figure 2).

\section{GENERAL PRESENTATION}

\section{Malignancy features}

NEN represents $2 \%$ of all cancers, being considered orphan disease because of their low prevalence in general population $(4,5)$. They are found at any age but typically in adults over 50 years, having either clear functional (secretor or hormonal) activity, either non-functional pattern $(1,4,6)$. The most frequent sites are pancreatic, gastrointestinal, pulmonary etc. $(4,7)$. Skin and soft tissue are exceptional sites of NEN, the majority are actually secondary spreading of priory known or unknown NEN of other locations (8). Little data have been published related to the topic $(8,9)$. Some cases reports showed invasion of dermis and subcutis, probably more frequent in older adults $(8,9)$.

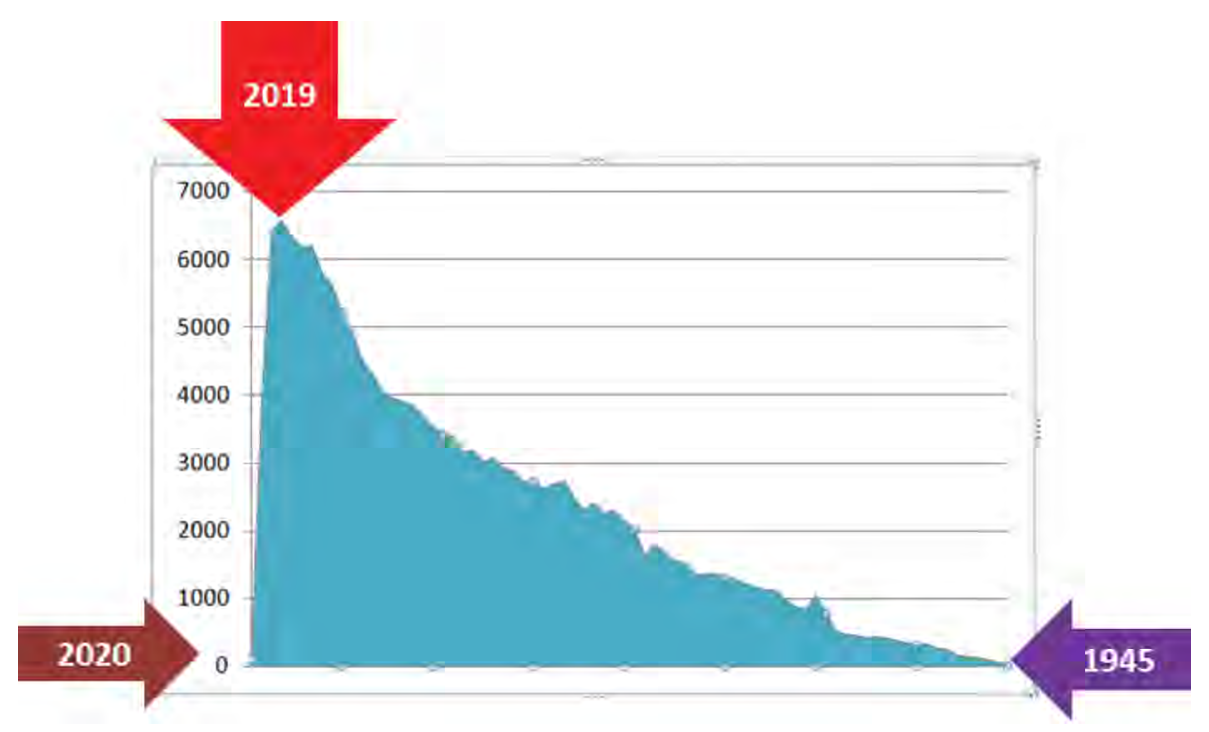

FIGURE 2. Unselected PubMed research of "neuroendocrine neoplasia" showed 172871 results and since 20176577 papers have been published up to present. (according Reference no. 5). The data correspond to the period of time 1945-2020. 
The entity has been named low-grade neuroendocrine carcinoma of the skin (LGNECS), also named primary cutaneous carcinoid tumour (PCTS) with a very low level of statistical evidence (9). The skin sites vary from chest wall to inguinal areas while the most frequent are head and neck (9). Since the incidence of primary skin NEN is exceptional they need to be differentiated from skin metastasis from NEN and other types of carcinomas like breast cancer $(8,9)$.

Histological reports show nest of cells having different dimensions and neuroendocrine features and lack of mucin secretion (9). The features are similar to NEN components of other sites (9). As seen in NEN diagnosis, the immunohistochemistry is essential like chromogranin A, synaptophysin, neuron specific enolase which are classical neuroendocrine markers and also non-neuroendocrine parameters useful for differential diagnosis are estrogens, androgens and progesterone receptors, GATA3, carcinoembryonic antigen (9). A part from clinical examination, dermoscopy remains a useful tool (10). The neuroendocrine component of the skin lesions may be associated with a carcinoma element, as also seen in breast lesions (11). No distinctive criteria of mix lesions are clearly up to present (11).

Merkel cell carcinoma represents the high grade NEN of skin meaning a more aggressive profile $(12,13)$. Opposite to this, LGNECS are asymptomatic nodules and due to their rarity a specific index of suspicion is necessary while specific investigations like whole body octreoscan might help $(12,13)$. Another potential scenario is the co-presence of carcinoid syndrome like diarrhoea, flush, respiratory problems like wheezing or bronchospasm etc. (13). Metastasis from primary skin NEN have been reported, especially at local lymph nodes $(13,14)$. PCTS seem to affect people of a median 66 years, equally between sexes, and their evolution is less aggressive than NEN metastasis at the same level (15). The neuroendocrine component of a mix tumour with a carcinoma of different types has an underestimated pathway of evolution (16). The value of Ki-67 remains a good prognostic factor (16).

Merkel cell carcinoma, also very rare, has a poor prognosis, with a $30 \%$ risk of local metastasis
$(17,18)$. The risk factors are either viral infections like Merkel cell polyomavirus, either long time exposure to ultraviolet light (especially in areas with intense ultraviolet light exposure) causing DNA mutations $(17,18)$. The prognostic is similar between the two factors $(17,18)$. Surgical removal is the first line therapy and adjuvant treatment is radiotherapy and chemotherapy $(18,19)$. Targeted therapies for gene mutations represent the next step to the future (19). Recent advance in registered in immunotherapy like PD-1/PD-L1 inhibitors, and antibodies against Merkel cell polyomavirus oncoproteins (20). After radiotherapy the "abscopal effect" has been described meaning the regression of distant metastasis after radiotherapy of primary skin lesions (20).

\section{Non-cancer aspects}

Dermatological manifestations of MEN (multiple endocrine neoplasia) type 1 syndrome involve neuroendocrine neoplasia of pancreatic and gastro-intestinal sites in addition to pituitary tumours and adrenal tumours including Cushing's syndrome and Conn syndrome $(21,22,23)$. Skin anomalies include facial angiofibromas, collagnomas and lipomas $(24,25)$. Glucagonoma may cause skin rash $(24,25)$. In MEN 2A syndrome dermal hyperneury and sclerotic fibromas are described (26).

\section{DISCUSSION}

We also mention the fact that, due the rarity of condition, they may be incidentally detected and histological report confirms the diagnosis and this is a general trend line in different areas of endocrinology or oncology due to the accessibly to different imaging techniques $(27,28)$. Generally, neuroendocrine mechanisms are involved in multiple aspects like skin aging, premenstrual syndrome etc. $(29,30)$.

\section{CONCLUSION}

Neuroendocrine neoplasia of the skin represents an exceptional finding of aggressive profile. Their prompt recognition may help the prognosis.

Conflict of interest: none declared Financial support: none declared

\section{REFERENCES}

1. Oronsky B, Ma PC, Morgensztern D, Carter CA. Nothing But NET: A Review of Neuroendocrine Tumors and Carcinomas. Neoplasia. 2017;19(12):991-1002.
2. Poiana C, Neamţu MC, Avramescu ET, Carsote M, Trifănescu R, Terzea D, Neamtu OM, Ferechide D, Danciulescu Miulescu R. The poor prognosis factors in $\mathrm{G} 2$ neuroendocrine tumor. Rom J Morphol Embryol. 2013;54(3 Suppl):717-20.

3. Poiana C, Neamtu MC, Avramescu ET, Carsote M, Trifanescu R, Terzea D, Neamtu 
OM, Danciulescu Miulescu R. The dedifferentiation of neuroendocrine tumor metastases: myth or reality? Rom J Morphol Embryol. 2013;54(1):201-3.

4. Inzani F, Petrone G, Rindi G. The New World Health Organization Classification for Pancreatic Neuroendocrine Neoplasia. Endocrinol Metab Clin North Am. 2018; 47(3):463-470.

5. https://www.ncbi.nlm.nih.gov/ pubmed/?term=neuroendocrine+neoplasia

6. Poiana C, Carsote M, Trifanescu R, Terzea D, Croitoru A. Case study of appendiceal carcinoid during pregnancy. J Med Life. 2012; 5(3):325-8.

7. Poiana C, Carsote M, Ardeleanu C, Terzea D, Avramescu ET, Neamtu MC, Miulescu $\mathrm{RD}$. The value of the immunohistochemistry in a case of gastric neuroendocrine tumor and thyroid metastasis. Rom J Morphol Embryol. 2011;52(1):187-92.

8. Adnan A, Basu S. Rare Site Primary Soft tissue Neuroendocrine Tumour with metastases and near-complete resolution with ${ }^{177}$ Lu-DOTATATE: documenting a Promising Clinical Application of Peptide Receptor Radionuclide Therapy. J Nucl Med Technol. 2019 Aug 10.

9. Goto K, Anan T, Nakatsuka T, Kaku Y, Sakurai T, Fukumoto T, Kimura T, Shibata A. Low-Grade Neuroendocrine Carcinoma of the Skin (Primary Cutaneous Carcinoid Tumor) as a Distinctive Entity of Cutaneous Neuroendocrine Tumors: A

Clinicopathologic Study of 3 Cases With Literature Review. Am J Dermatopathol. 2017;39(4):250-258.

10. Babino G, Lallas A, Longo C, Moscarella E, Alfano R, Argenziano G. Dermoscopy of melanoma and non-melanoma skin cancer. $G$ Ital Dermatol Venereol. 2015;150(5):507-19.

11. Asioli S, Foschini MP, Masetti R, Eusebi V. Working formulation of neuroendocrine tumors of the skin and breast. Endocr Pathol. 2014;25(2):141-50.

12. Chen TY, Morrison AO, Susa J, Cockerell CJ. Primary low-grade neuroendocrine carcinoma of the skin: An exceedingly rare entity. J Cutan Pathol. 2017;44(11):978-981.

13. Okabayashi A, Nakagawa K, Shimizu N, Tohda-Kinoshita R, Goto K. Case of low-grade neuroendocrine carcinoma of the skin presenting metastases to lymph nodes and peritoneum. J Dermatol. 2019; 46(8):720-723.

14. MacKenzie DN, McCormick CS, Morris RJ. Lymph node metastasis from a primary skin carcinoid tumour. Br J Plast Surg. 2003; 56(7):718-21.

15. Jedrych J, Pulitzer M. Primary carcinoid tumor of the skin: A literature review. Int $\mathrm{J}$ Surg Pathol. 2014;22(2):129-35.

16. Miquelestorena-Standley E, Dujardin F, Arbion F, Touzé A, Machet L, Velut S, Guyétant S. Recurrent primary cutaneous mucinous carcinoma with neuroendocrine differentiation: Case report and review of the literature. J Cutan Pathol. 2014; 41(8):686-91.

17. Becker JC, Stang A, DeCaprio JA, Cerroni L, Lebbé C, Veness M, Nghiem P. Merkel cell carcinoma. Nat Rev Dis Primers. 2017; 3:17077.

18. Pulitzer M. Merkel Cell Carcinoma. Surg Pathol Clin. 2017;10(2):399-408.

19. Cassler NM, Merrill D, Bichakjian CK, Brownell I. Merkel Cell Carcinoma Therapeutic Update. Curr Treat Options Oncol. 2016;17(7):36.

20. Robinson CG, Tan D, Yu SS. Recent advances in Merkel cell carcinoma. F1000Res. 2019 Nov 26;8.

21. Poiana C, Carsote M, Chirita C, Terzea D, Paun S, Beuran M. Giant adrenal cyst: case study, J Med Life 2010;3(3):308-313.
22. Poiana C, Chirita C, Carsote M, Hortopan D, loachim D, Corneci CM, Stanescu B. Adrenal and Pituitary Incidentalomas in a Case of Cushing's Syndrome. Chirurgia 2013; 6(108):886-891.

23. Paduraru DN, Nica A, Carsote M, Valea A Adrenalectomy for Cushing's syndrome: do's and don'ts. Journal of Medicine and Life. 2016;4(9):334-341.

24. Saggini A, Brandi ML. Skin lesions in hereditary endocrine tumor syndromes. Endocr Pract. 2011;17 Suppl 3:47-57.

25. Pérez AD, Yu S, North JP. Multiple cutaneous collagenomas in the setting of multiple endocrine neoplasia type $1 . J$ Cutan Pathol. 2015;42(11):791-5.

26. Alegría-Landa V, Jo-Velasco M, Robledo M, Requena L. Dermal Hyperneury and Multiple Sclerotic Fibromas in Multiple Endocrine Neoplasia Type 2A Syndrome. JAMA Dermatol. 2017;153(12):1298-1301.

27. Gheorghisan-Galateanu AA, Carsote M, Valea A. Incidentaloma: from general practice to specific endocrine frame. J Pak Med Assoc. 2017;67(6):917-922.

28. Gheorghiu M, Hortopan D, Dumitrascu A, Caragheorgheopol A, Stefanescu A, Trifanescu R, Niculescu D, Baciu I, Carsote M, Poiana C, Badiu C, Coculescu M. Age-related endocrine tumors: Nonfunctioning adrenal tumors as compared to pituitary adenomas. Acta Endocrinologica, 2009; V(3):371-384

29. Poiana C, Musat M, Carsote M, Chirita C. Premenstrual dysphoric disorder: Neuroendocrine interferences. Rev Med Chir Soc Med Nat lasi. 2009;113(4):996-1000.

30. Bocheva G, Slominski RM, Slominski AT. Neuroendocrine Aspects of Skin Aging. Int J Mol Sci. 2019;20(11). 